\title{
Multi-location Based Evaluation of tef Genotypes for Grain Yield Stability and Agronomic Performance in Western Ethiopian High Lands
}

\author{
Girma Chemeda \\ Bako Agricultural Research Center, P.O. Box 3, Bako, Ethiopia
}

\begin{abstract}
Tef [Eragrostis tef (Zucc.) Trotter] is extensively cultivated and most important cereal crop in Ethiopia in terms of production, consumption and cash crop value and grown on about 3 million hectares annually. Because of its gluten-free proteins and slow release carbohydrate constituents, tef is recently being advocated and promoted as health crop at the global level. However, the productivity of tef is very low compared to other cereals mainly due to lack of high yielding and lodging tolerant cultivars. For this purpose, several genotypes were evaluated under different breeding stages in multi-locations so as to screen and reach at stable, high yielding and stress tolerant varieties. Accordingly, the year 2017/18 twenty five recombinant inbred- lines were tested in preliminary variety trial out of which sixteen genotypes were advanced to regional variety trial and tested in 2018/19 and 2019/20 in multi-locations. Finally the combined analysis of variance across the three locations revealed highly significant $(\mathrm{p}<0.01)$ difference among genotypes for grain yield, days to mature, plant height, panicle length, lodging \%, effective tiller, and crop stand. Among tested genotypes three, RIL 76B, RIL 46 and RIL 43A found to be stable, high yielder and lodging tolerant across the tasted locations with grain yield advantage of $26.62 \%, 19.77 \%$ and $12.72 \%$ over the standard check respectively. Therefore based on their high yield and stable performance, genotypes RIL 76B, RIL 46 and RIL 43A were promoted to Variety Verification Trial (VVT) evaluation and for possible release.
\end{abstract}

Keywords: Eragrostis, Genotypes, stability, tef

DOI: $10.7176 / \mathrm{JBAH} / 10-17-06$

Publication date:September $30^{\text {th }} 2020$

\section{Introduction}

Tef [Eragrostis tef (Zucc.) Trotter] is a self pollinated warm season annual grass with the advantage of C4 photosynthetic pathway (Miller, 2010). Tef is among the major Ethiopian cereal crops grown on over 3 million hectares annually (CSA, 2018), and serving as staple food grain for over 70 million people. Tef grain is primarily used for human consumption after baking the grain flour into popular cottage bread called "injera". Tef has an attractive nutritional profile, being high in dietary fiber, iron, calcium and carbohydrate and also has high level of phosphorus copper, aluminum, barium, thiamine and excellent composition of amino acids essential for humans (Hager et al.,2012; Abebe et al.,2007; USDA 2015). The straw (chid) is an important source of feed for animals. Generally, the area devoted to tef cultivation is increased because both the grain and straw fetch high domestic market prices. Tef is also a resilient crop adapted to diverse agro-ecologies with reasonable tolerance to both low (especially terminal drought) and high (water logging) moisture stresses. Tef, therefore, is useful as a low-risk crop to farmers due to its high potential of adaptation to climate change and fluctuating environmental conditions (Balsamo et al., 2005). Nevertheless, until recently, tef was considered as "orphan" crop: one receiving no international attention regarding research on breeding, agronomic practices or other technologies applicable to smallholder farmers.

The continued cultivation of tef in Ethiopia is accentuated by the following relative merits: 1) as the predominant crop, tef is grown in a wide array of agro-ecologies, cropping systems, soil types and moisture regimes; 2) with harvests of 4.75 million tons of grain per year from about 3 million ha. Tef constitutes about $23.85 \%$ of the total acreage and has about $17.26 \%$ contribution in grain production of cereals in Ethiopia followed by maize which accounts for about $21 \%$ of the acreage and $31 \%$ of the overall cereal grain production (CSA, 2018). 3 ) The values of the grain and straw contribute about four billion Birr to the national GDP; 4) it has a good export market, 5) tef grain has got relatively good nutritive value especially since it contains relatively high amounts of iron, calcium and copper compared to other cereals. Because of its gluten-free proteins and slow release carbohydrate constituents, tef is recently being advocated and promoted as health crop at the global level (Ketema S 1993: Spaenij-Dekking et al., 2005: kebebew Asefa et.; al 2013; Assefa et.; al. 2017). The most important bottlenecks constraining the productivity and production of tef in Ethiopia are: i) low yield potential of farmers' varieties under widespread cultivation; ii) susceptibility to lodging particularly under growth and yield promoting conducive growing conditions; iii) biotic stresses such as diseases, weeds and insect pests; iv) abiotic stresses such as drought, soil acidity, and low and high temperatures; v) the culture and labor intensive nature of the tef husbandry; vi) inadequate research investment to the improvement of the crop as it lacks global attention due to 
localized importance of the crop coupled with limited national attention; and vii) weak seed and extension system (kebebew Asefa et.; al 2013; Assefa et.; al. 2017). Therefore the objective of this activity was to develop and release high yielding, lodging and diseases tolerant tef varieties for potential growing areas of western parts of the country. Therefore, the objective of the current study was to develop and release high yielding, lodging, pest and acidic soils tolerant tef varieties for Western parts of tef growing areas of Ethiopia

\section{Materials and Methods}

The experimental materials were 89 recombinant tef inbred lines received from by Debre Zeit Agricultural Research Center. The materials were initially developed through crossing made between mutant tef inbred lines (GA-10-3) and quncho tef variety (DZ-Cr-387) after stringent selections to eight generations. The material were tested in Nursery during 2016/17 at Shambu sub-site and reduced to twenty five genotypes and evaluated in preliminary variety trial for one year during 2017/18. Eighteen genotypes including the checks were evaluated in multi-location so as to see their adaptability, stability, yield, and resistance/tolerance to major tef diseases in the main cropping season during 2018/2019 and 2019/2020 in regional variety trial. The experiment was conducted at Shambu, Gedo and Arjo sub site using Randomized Complete Block design with three replications on a plot size (experimental unit) of $2 \mathrm{~m} \times 2 \mathrm{~m}(4 \mathrm{~m} 2)$ each with $0.2 \mathrm{~m}$ of row spacing. The distance between block was $1.5 \mathrm{~m}$ and between plots was $1.0 \mathrm{~m}$. Fertilizer rate of 100/50 kg DAP/UREA at planting and $10 \mathrm{~kg} / \mathrm{ha}$ of seed rate will used. Other agronomic practices were applied uniformly as required. Data on days to emergence, days to heading, days to maturity, panicle length, plant height, panicle length, shoot biomass, lodging \%, effective tiller, Stand \%, grain yield per plot and disease score (1-9 scale) was collected and subjected to statistical analysis using SAS statistical software.

\section{Results and Discussion}

The combined analysis of variance across the three locations revealed highly significant $(\mathrm{p}<0.01)$ difference among genotypes for plant height, panicle length, shoot biomass, lodging \% and grain yield qt/ha (Table 2). Genotype RIL 76B, RIL 46 and RIL 43A gave the highest grain yield (2278.97Kg/ha) followed by genotype RIL 46 (2155.71 $\mathrm{Kg} / \mathrm{ha})$ and RIL 43A (2028.68Kg/ha). The standard check variety Dursi gave $1799.81 .24 \mathrm{Kg} / \mathrm{ha}$. The three candidate genotypes had yield advantage of $26.62 \%, 19.77 \%$, and $12.72 \%$ over the standard check respectively (Table 1). In agreement with this finding; previous studies of Genotype x environment on 22 tef genotypes at four locations in Southern regions of Ethiopia have indicated significant variations in grain yield for the tested genotypes (Ashamo M, Belay G 2012). Similar study on phenotypic diversity in tef germplasm in a pot experiment using 124 single panicle sample collection showed substantial variability for traits such as plant height, panicle length, maturity, seed color, seed yield, lodging and panicle type (Malak-Hail et al.; 1965).

The combined analysis of variance for biomass depicted non significant $(\mathrm{P}<0.05)$ difference among the tested genotypes. The analysis of variance for lodging percent revealed that low percent for genotype RIL 76B (2.51\%) followed by RIL 43A (2.70\%) and RIL 46 (2.91\%) respectively. The stability study indicated that RIL 76B, RIL46 and RIL found to be stable and high yielders across the tasted locations with grain yield advantage of $26.62 \%$, $19.77 \%$ and $12.72 \%$ respectively over the check (Table 1). The GGE bi-plot analysis revealed that three candidate genotypes showed stable adaptability across the tested locations (Fig 1). They were also high yielders than the best check and fall relatively close to the concentric circle near to average environment axis, suggesting their potential for wider adaptability with better grain yield performance.

Table 1. Mean grain yield across years and Locations

\begin{tabular}{|c|c|c|c|c|c|c|c|c|c|}
\hline & 2018 & 2019 & 2018 & 2019 & 2018 & 2019 & GY Kg/ha & advantage & Rank \\
\hline RIL NO.76B & 2422.667 & 2365.42 & 2305.83 & 2287.83 & 2111.67 & 2180.42 & 2278.97 & 26.62 & 1 \\
\hline RIL NO.46 & 2203.167 & 2234 & 2160 & 2232.75 & 2051.67 & 2052.67 & 2155.71 & 19.77 & 2 \\
\hline RIL NO.43A & 2112.5 & 2105.67 & 2045.83 & 2046.25 & 1884.17 & 1977.67 & 2028.68 & 12.72 & 3 \\
\hline RIL NO.66 & 1955.833 & 1976.42 & 1977.5 & 2068.08 & 1849.17 & 1958.75 & 1964.29 & 9.14 & 4 \\
\hline Dursi (check) & 1865.833 & 1864.75 & 1812.17 & 1761.58 & 1746 & 1748.5 & 1799.81 & & 5 \\
\hline RIL NO.65 & 1540.833 & 1568.67 & 1874.17 & 1529.42 & 1675.83 & 1623.67 & 1635.43 & & 6 \\
\hline (RIL NO.80) & 1813.167 & 1316.8 & 1985.17 & 1373.08 & 1697.5 & 1328.08 & 1585.62 & & 7 \\
\hline RIL NO.44 & 1726.667 & 1490.33 & 1575.83 & 1423.25 & 1718.33 & 1520.42 & 1575.80 & & 8 \\
\hline RIL NO.53 & 1637.777 & 1389.67 & 1784.17 & 1336.25 & 1628.33 & 1416.92 & 1532.19 & & 9 \\
\hline RIL NO.74 & 1462.5 & 1520.83 & 1693.33 & 1418 & 1605.83 & 1428.17 & 1521.44 & & 10 \\
\hline RIL NO.72 & 1525.833 & 1321.92 & 1724.17 & 1379.83 & 1685 & 1387.08 & 1503.97 & & 11 \\
\hline RIL NO.52 & 1698.333 & 1141.58 & 2079.17 & 1115.5 & 1802.5 & 1111.17 & 1491.38 & & 12 \\
\hline Local Check & 1607.5 & 1250.5 & 1759.5 & 1322.83 & 1720 & 1256.58 & 1486.15 & & 13 \\
\hline RIL NO.61 & 1576.667 & 1367 & 1775 & 1352.75 & 1630 & 1202.5 & 1483.99 & & 14 \\
\hline RIL NO.49 & 1575.833 & 1231.33 & 1864.17 & 1292.17 & 1663.33 & 1263.75 & 1481.76 & & 15 \\
\hline RIL NO.85 & 1585 & 1355.33 & 1726.67 & 1331.5 & 1583.33 & 1275.83 & 1476.28 & & 16 \\
\hline RIL 91A Check & 1693.333 & 1224 & 1700 & 1255.92 & 1520 & 1300.75 & 1449.00 & & 17 \\
\hline RIL NO.7 & 1525.833 & 1154.42 & 1908.33 & 1179.17 & 1388.33 & 1122.08 & 1379.69 & & 18 \\
\hline
\end{tabular}




\begin{tabular}{|c|c|c|c|c|c|c|c|c|c|}
\hline & 2018 & 2019 & 2018 & 2019 & 2018 & 2019 & GY Kg/ha & advantage & Rank \\
\hline Mean & 1751.63 & 1548.81 & 1875.06 & 1539.23 & 1720.06 & 1508.61 & & & \\
\hline LSD & 143.54 & 359.18 & 162.73 & 360.89 & 237.88 & 377.36 & & & \\
\hline $\mathrm{CV}$ & 4.94 & 13.98 & 5.23 & 14.13 & 8.33 & 15.07 & & & \\
\hline F-test & $* * *$ & $* * *$ & $* * *$ & $* * *$ & $* * *$ & $* * *$ & & & \\
\hline
\end{tabular}

Note: $\mathrm{GY}=$ grain yield, $\mathrm{RIL}=$ recombinant inbred line, $* * *=$ highly significant, $\mathrm{LSD}=$ least significant difference, $\mathrm{CV}=$ coefficient of variation

Table 2. Mean Agronomic Traits across years and Locations

\begin{tabular}{lccccccccc}
\hline Genotype & DH & DM & PH & ET & PL & LD & ST & LR & SBM \\
\hline RIL NO 76B & 71.11 & 134.22 & 94.28 & 4.22 & 36.31 & 2.51 & 2.22 & 1.93 & 12.74 \\
RIL NO.46 & 71.11 & 136.06 & 94.81 & 3.97 & 35.36 & 2.91 & 2.67 & 1.93 & 7.86 \\
RIL NO.43A & 71 & 135.17 & 93.24 & 4.67 & 34.64 & 2.7 & 3.78 & 1.87 & 7.76 \\
RIL NO.66 & 72.5 & 136.72 & 99.32 & 3.9 & 37.98 & 3.24 & 2.67 & 3.03 & 7.24 \\
Dursi (check) & 72.11 & 135 & 102.23 & 4.49 & 39.31 & 2.31 & 1.67 & 1.69 & 7.64 \\
RIL NO.65 & 70.17 & 136.56 & 99.13 & 4.13 & 37.44 & 2.95 & 2.22 & 2.67 & 6.69 \\
RIL NO.80 & 70.17 & 135.94 & 97.87 & 3.96 & 35.68 & 3.03 & 3 & 2.53 & 5.79 \\
RIL NO.44 & 73.28 & 134.39 & 97.98 & 4.35 & 36.72 & 2.83 & 2.78 & 2 & 7.54 \\
RIL NO.53 & 71.06 & 136.67 & 96.57 & 3.86 & 35.98 & 3.17 & 2 & 3.37 & 6.71 \\
RIL NO.74 & 68.44 & 137.28 & 94.9 & 4.21 & 35.63 & 3.67 & 2.89 & 2.29 & 6.29 \\
RIL NO.72 & 71.28 & 136.61 & 98.13 & 3.66 & 37.49 & 3.61 & 2.67 & 2.85 & 6.82 \\
RIL NO.52 & 71.11 & 135.17 & 99.54 & 3.97 & 38.11 & 3.27 & 2.44 & 2.43 & 6.38 \\
Local check & 71 & 134.5 & 97.48 & 4.12 & 37.2 & 3.52 & 2.78 & 2.5 & 6.82 \\
RIL NO.61 & 68.11 & 132.11 & 87.64 & 3.89 & 30.79 & 2.94 & 2.67 & 1.98 & 6.07 \\
RIL NO.49 & 71.22 & 137.5 & 99.44 & 3.62 & 38.58 & 3.24 & 2.56 & 2.29 & 7.25 \\
RIL NO.85 & 72.5 & 134 & 95.57 & 4.03 & 36.79 & 3 & 2.89 & 2.23 & 6.36 \\
RIL 91A Check & 69.5 & 133.22 & 90.78 & 4.16 & 33.67 & 2.58 & 3 & 2.3 & 6.39 \\
RIL NO.73 & 73.44 & 136.61 & 94.06 & 3.69 & 35.17 & 3.44 & 3 & 3.16 & 6.36 \\
\hline Grand Mean & $\mathbf{7 1 . 0 6}$ & $\mathbf{1 3 5 . 4 3}$ & $\mathbf{9 6 . 2 8}$ & $\mathbf{4 . 0 5}$ & $\mathbf{3 6 . 2 7}$ & $\mathbf{3 . 0 5}$ & $\mathbf{2 . 6 6}$ & $\mathbf{2 . 3 9}$ & $\mathbf{7 . 1 5}$ \\
LSD & $\mathbf{3 . 1 9}$ & $\mathbf{1 . 4 1}$ & $\mathbf{3 . 9 6}$ & $\mathbf{0 . 4 1}$ & $\mathbf{1 . 6 7}$ & $\mathbf{0 . 6 1}$ & $\mathbf{0 . 3 9}$ & $\mathbf{0 . 6 4}$ & $\mathbf{3 . 4 5}$ \\
CV & $\mathbf{5 . 4 4}$ & $\mathbf{1 . 5 3}$ & $\mathbf{5 . 3 1}$ & $\mathbf{1 3 . 1 8}$ & $\mathbf{6 . 9 5}$ & $\mathbf{1 4 . 3}$ & $\mathbf{2 2 . 0 3}$ & $\mathbf{2 2 . 4 1}$ & $\mathbf{6 9 . 7 4}$ \\
F.test & $*$ & $* * *$ & $* * *$ & $* * *$ & $* * *$ & $* * *$ & $* * *$ & $* * *$ & ns
\end{tabular}

Note: $*=$ significant, $* * *=$ highly significant, $\mathrm{ns}=$ none significant, $\mathbf{R I L}=$ recombinant inbred line, $\mathbf{D H}=$ days to heading, $\mathbf{D M}=$ days to maturity, plant height, $\mathbf{E T}=$ effective tiller, $\mathbf{P L}=$ panicle length, $\mathrm{LD}=$ lodging $\%, \mathbf{S B M}=$ shoot biomass, $\mathbf{S T}=$ Stand \%, $\mathbf{L R}=$ leaf rust, $\mathrm{LSD}=$ least significant difference, $\mathrm{CV}=$ coefficient of variation

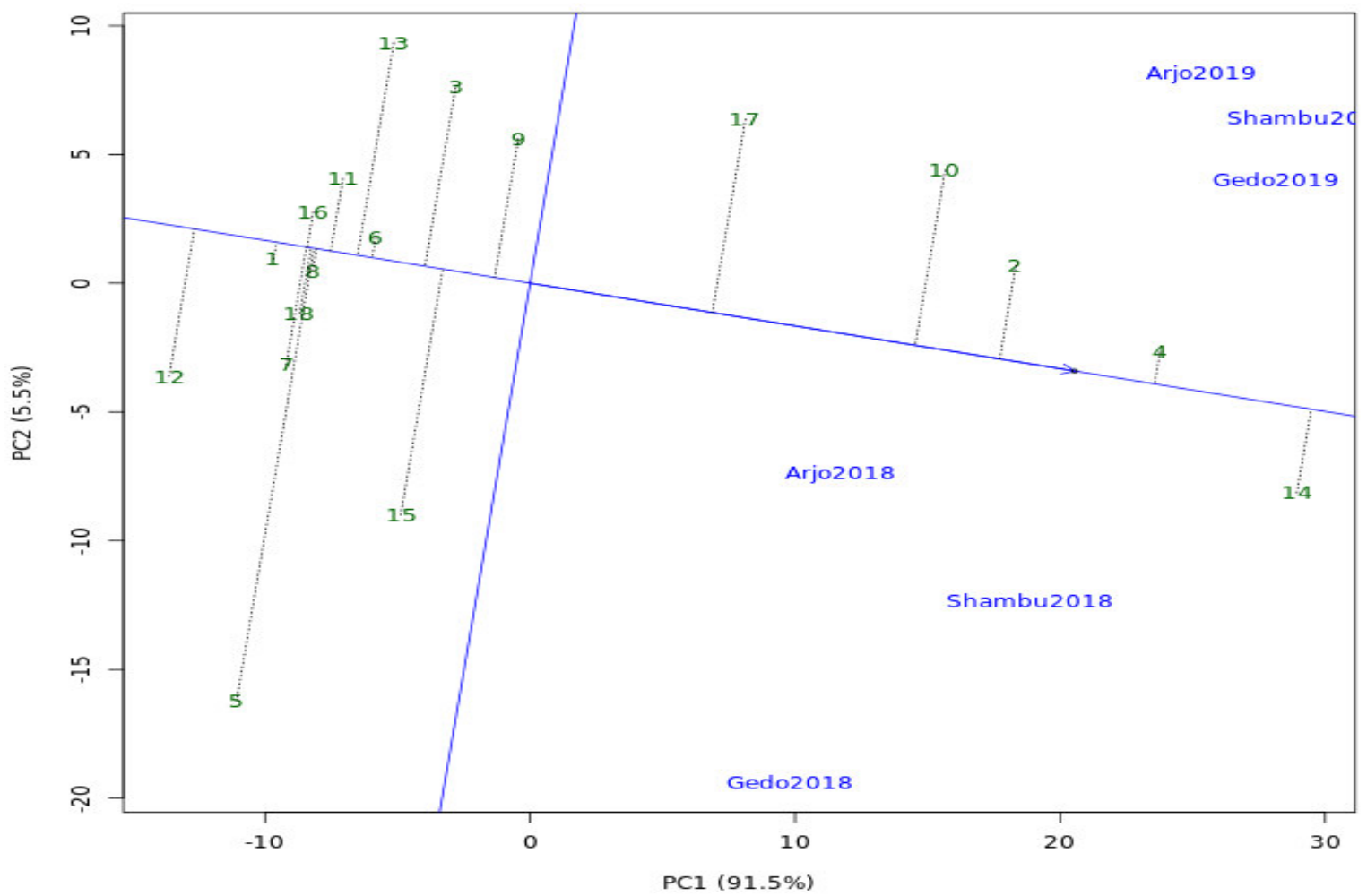

Figure1. GGE bi-plot: mean vs. stability 


\section{Conclusion and Recommendation}

Combined analysis of variance for the genotypes portrayed highly significant differences for days to maturity, effective tillers, plant height, panicle length, lodging \% , crop stand, leaf rust and grain yield kg/ha. Genotype RIL 76B, RIL 46 and RIL 43A were found stable, high yielders and lodging tolerant across the tasted locations with grain yield advantage of $26.62 \%, 19.77 \%$ and $12.72 \%$ over the standard check respectively. As a result of these all merits, these three genotypes were identified as candidate varieties to be verified at three locations the coming cropping season.

\section{Acknowledgment}

The author acknowledges Oromia Agricultural Research Institute and Bako Agricultural Research Center for fulfilling all the necessary inputs to undertake this activity. I am also grateful to all research staffs and workers of Bako Agricultural research Center.

\section{References}

Abebe Y, Bogale A, Hamgidge, KM, Stoecker BJ, Bailey K, Gibson RS, (2007). Phytate, zinc, iron, and calcium content of selected raw and prepared foods consumed in rural Sudama, Southern Ethiopia and implication of bioavailability. J food Compo Anal.20:161-168.

Ashamo M, Belay G (2012). Genotype x Environment Interaction Analysis of Tef Grown in Southern Ethiopia Using Additive Main Effects and Multiplicative Interaction Model. Journal of Biology Agriculture and Healthcare 2: 66-72.

Assefa K, Chanyalew S, Tadele Z (2017). Tef, Eragrostis tef (Zucc.) Trotter. In: Patil JV (ed) Millets and sorghum, biology and genetic improvement. Wiley, Hoboken, pp 226-266

Balsamo R A, Willigen C V,Boyko W, Farrent L (2005). Retention of mobile water during dehydration in the desiccation-tolerant grass Eragrostis nindeensis' . Physiol Planetarium.134:336-342.

Central Statistical Agency(2015). The federal Democratic Republic of Ethiopia. Central Statistical Agency Agricultural Sample Survey 2015: Report on Area and Production of Major Crops (Private peasant Holdings, Maher Season), Volume III. Addis Ababa,Ethiopia.

Hanger AS, Wolter A, JacobF, Zannini E, Arendt EK (2012). National properties and ultera-structure of commercial gluten free flours from different botanical sources compared to wheat flours. J Cereal Sci.56:239247.

Kebebew Assefa, Solomon Chanyalew; and Gizaw Metaferia (2013). Conventional and Molecular Tef Breeding, Proceedings of the Second International Workshop,November 7-9, 2011, Debre Zeit, Ethiopia

Ketema S (1993). Tef, Eragrostis tef (Zucc.) Trotter: breeding, Genetic Resources, Agronomy, Utilization and Role in Ethiopian Agricu

Melak-Hail Mengesha,Picket R. C., Davis R. L (1965). Genetic variability and interrelationship of characters in teff, Eragrsotis tef (Zucc.) Trotter, Crop Sci. 5: 155-157. Miller, D (2010) Teff guide 3rd edition, viewed on 24 September 2012, http://www.calwestseeds.com.product/teff

Spaenij-Dekking L, Kooy-Winkelaar Y and Koning F (2005).The Ethiopian cereal tef in celiac disease. N. Engl. J. Med. 353: 16

USDA (2015). National Nutrient Database for Standard Reference Release 27, United States Department of Agriculture, USA 